УДК 615.12-057.15:658.310.9

СОЦИОЛОГИЧЕСКОЕ ИЗУЧЕНИЕ КОНФЛИКТНЫХ СИТУАЦИЙ В АПТЕЧНОЙ ОРГАНИЗАЦИИ

\author{
А.В. Смирнов, Н.Ю. Чернухина
}

Пятигорский медико-фармацевтический институт - филиал ГБОУ ВПО ВолгГМУ Минздрава России, г. Пятигорск

\title{
SOCIALOGICAL STUDY OF CONFLICT SITUATIONS IN PHARMACY ORGANIZATION
}

\section{A.V. Smirnov, N.Yu. Chernukhina}

Pyatigorsk Medical and Pharmaceutical Institute - a branch of Volgograd State Medical University, Pyatigorsk

$$
\text { E-mail: vizor.pmfi@gmail.com }
$$

В статье приводятся результаты социологических исследований в аптечной сети г. Ростова-на-Дону.

Ключевые слова: конфликты в аптечной организации, социологические исследования, составление анкеты покупателя.

Конфликтная ситуация в аптеке. Можно ли её предотвратить? А если конфликт всё же возник, как из него выйти? Как поступить, если покупатель начинает грубить, необоснованно обвиняя продавца?

А если конфликт не разрешён? Чем это грозит обеим сторонам? Кто теряет больше? Ведь известно, что о своём негативном опыте покупки или просто визита в магазин покупатели сами рассказывают десяткам своих знакомых. Нередко разгневанные покупатели распространяют рассказы о возникшем конфликте в Интернете...

В этой сложной ситуации всё зависит от профессиональной подготовки провизора, его способности «держать удар» и справляться с собственными эмоциями. Но и этого мало. В основе предотвращения возможности и умения уладить конфликт с покупателями стоит
The article presents results of sociological researches in pharmacy organization of Rostov-on-Don.

Keywords: conflicts in pharmacy organization, sociological researches, customer questionary making.

корпоративная культура и корпоративные стандарты обслуживания.

Нельзя забывать об одном: в конфликте между продавцом и покупателем терпит поражение всегда одна сторона аптечная организация.

Для выявления возникших в прошлом конфликтных ситуаций был проведён опрос аптечных работников. Социологическое исследование проводилось в аптечных организациях частной аптечной сети «ЮГ-Фарма» (г. Ростов-на-Дону).

Проводился опрос аптечных работников о случаях проявления конфликтных ситуаций и методах их разрешения.

В соответствии с особенностями проведения анкетного опроса посетителей аптечных организаций, описанными в литературе, была разработана «Анкета потребителя».

Для упрощения обработки заполненных анкет в анкету были включены 14 
вопросов закрытого типа, но для выявления конкретных конфликтных ситуаций для анкетируемых был предложен вопрос открытого типа: «Если у вас возникала конфликтная ситуация в нашей или другой аптеке, просим кратко описать её...».

Как показали результаты опроса специалистов аптечных организаций, большинство возникающих в аптечной организации конфликтов связаны с отсутствием в наличии требуемых покупателями лекарственных препаратов, а также с требованием отпуска рецептурных ЛП без рецепта. Как отметили респонденты, большинство конфликтов, связанных с отсутствием препаратов, решается, когда покупателям предлагается заказать отсутствующий ЛП и приобрести его в течение 3-4 дней.

Несколько сложнее успокоить разгневанного посетителя аптечной организации, который требует предоставить ему ЛП, отпускаемый строго по рецепту. В большинстве случаев приходится для разрешения конфликта привлекать зав. аптекой, который ссылается на наличие нормативных документов и предоставляет их в случае необходимости.

Также отмечено несколько случаев претензий покупателей по поводу возврата приобретённых ЛП. Аптечные работники отметили, что в таких обстоятельствах покупатели часто проявляют особую фантазию, например, отмечались ссылки на телевизионную рекламу, БАДы, особо эффективные экстрасенсорные методы, которые якобы эффективней купленных ЛП.

В то же время сотрудники аптеки сошлись на том, что в целом отношение покупателей к работникам аптечной организации достаточно благожелательное и конфликтные ситуации возникают редко.

Можно привести пример конфликтной ситуации, когда рассерженная покупательница дошла до Министерства здравоохранения Ростовской области с требованием заменить ей отечественный препарат на импортный. Речь при этом шла об ацетилсалициловой кислоте (аспирине).

Затем оказалось, что данная покупательница давно находится на учёте в психоневрологическом диспансере и является недееспособной...

Для изучения мнений потребителей вначале анкеты были просто разложены на одном из прилавков нескольких аптечных организаций указанной аптечной сети для заполнения покупателями, но к большому сожалению не заполнялись.

Поэтому было принято решение о проведении устного опроса покупателей нашей аптечной организации с одновременным заполнением разработанной анкеты.

В течение 3 недель покупателям предлагалось заполнить анкету, в результате было получено 47 полностью заполненных анкет, пригодных для обработки.

Полученные анкеты были проанализированы и подвергнуты статистической обработке.

В результате анализа полученных анкет были получены следующие данные.

В опросе согласились участвовать 39 женщин (83\%) и 8 мужчин.

Большинство опрошенных 46 человек $(97,9 \%)$ проживают в городе, а один человек живёт в сельской местности.

Респонденты достаточно часто посещают аптечные организации, так $85,1 \%$ из них бывают в аптеке 1-2 раза в месяц.

Всего 3 человека $(6,4 \%)$ отметили, что являлись свидетелями конфликтной ситуации в аптеке, но никто $(0 \%)$ не сознался, что являлся инициатором такой ситуации...

В то же время 7 участников опроса $(14,9 \%)$ заявили, что требуют «Книгу жалоб и предложений» при посещении аптеки.

На вопрос «Наиболее частые причины возникновения конфликтов» ни один из интервьюированных не ответил... 
На вопрос «Как Вы думаете, кто обычно виноват в конфликте?» тем не менее 10 человек из 47 ответили, что виноват работник первого стола.

При этом 22 респондента отметили, что конфликт выводит их из себя.

При ответе на вопрос: «Если конфликт любого рода (не только в аптеке) действует на Вас отрицательно, какие средства и методы Вы используете для восстановления психологического равновесия?» было установлено, что большинство опрошенных следуют советам провизоров и врачей-специалистов.

На вопрос: «Используете ли вы какие-либо лекарственные препараты для восстановления психологического равновесия?» большинство респондентов ответили, что используют «Седативные (успокаивающие) средства растительного происхождения» (62\%).

На вопрос: «Какая сумма в среднем тратится на Ваши препараты ежемесячно?» большинство покупателей ответили, что приобретают товары в аптеке на сумму от ста до пятисот рублей.

К большому сожалению, ни один из анкетируемых не захотел описать конфликтную ситуацию, возникшую у них в аптечной организации.

\section{Выводы}

Дисфукциональный конфликт между провизором и посетителем аптечной организации должен быть исключен, это поможет аптечной организации занять лидирующее положение на рынке и заработать или поддерживать хорошую репутацию.

Необходимо попытаться понять другую сторону, вникнуть в её положение и состояние. Конфликт - не битва, и дело здесь совсем не в том, чтобы, поразить противника. Разрешая какую-то конкретную проблему, возникший спор, необходимо помочь достигнуть более глубокого взаимопонимания, укрепить доброе согласие. В результате конфликты будут возникать все реже и реже.

Для выявления конфликтных ситуаций в аптечной организации был проведён опрос аптечных работников.

Изучены мнения потребителей о конфликтных ситуациях в аптечных организацияX.

При проведении анкетного опроса покупателей выяснилось, что респонденты достаточно часто отвечали неискренне, что требует более углублённых исследований в указанной области.

\section{Библиографический список}

1. Анкетные опросы [Электронный ресурс]. - Режим доступа: http://edu.dvgups.ru/METDOC/CGU/SOTS_KULT_SERVIS/MET_N_ISL/METOD/U_P/frame /6.htm.

2. Анкетный опрос: виды, способы, преимущества, недостатки [Электронный ресурс]. - Режим доступа: http://socupr.blogspot.ru/2009/11/blog-post_4433.html.

3. Как успешно работать с конфликтными покупателями, клиентами? [Электронный peсурс]. - Режим доступа: http://bizataka.ru/menedzhment/marketing/kak-uspeshno-rabotat-skonfliktnymi-pokupatelyami-klientami.html.

4. Конфликт в аптеке: как выйти сухим, живым и невредимым [Электронный ресурс]. Режим доступа: http://www.apteka.ua/article/7491.

5. Конфликт в торговом зале - проигравший всегда один [Электронный ресурс]. - Peжим доступа: http://psystars.ru/publications/40.

6. УМ2. Анкетный опрос: технология подготовки и проведения. [Электронный ресурс]. - Режим доступа: http://marketingforfriendspart2.blogspot.ru/2012/01/2_23.html. 
Смирнов Александр Викторович - кандидат фармацевтических наук, дочент кафедры организачии и экономики фармачии Пятигорского медико-фармачевтического института- филиала ГБОУ ВПО ВолгГМУ Минздрава России, г. Пятигорск. Область научных интересов: изучение конфликтных ситуаџий в аптечных организациях, информационные технологии в фармацевтической отрасли E-mail: vizor.pmfi@gmail.com.

Чернухина Надежда Юрьевна - студентка заочного отделения Пятигорского медико-фармацевтического института- филиала ГБОУ ВПО ВолгГМУ Минздрава России, 2. Пятигорск. Область научных интересов: изучение конфликтных ситуаций в аптечных организаичиях 


\section{ПРАВИЛА ПОДАЧИ РУКОПИСЕЙ}

(составлены с учетом «Единых требований к рукописям, предоставляемым в биомедицинские журналы», разработанных Международным комитетом редакторов медицинских журналов)

«Фармация и фармакология» - научно-практический рецензируемый журнал, посвященный широкому спектру современных проблем в рассматриваемой области.

В журнале имеются следующие разделы: 1) обзоры, лекции, 2) фармакогнозия, ботаника, 3) фармацевтическая технология и биотехнология, 4) фармацевтическая и токсикологическая химия, 5) фармакология и клиническая фармакология, 6) информационные технологии в фармации, 7) управление и экономика фармации, 8) экономика и менеджмент медицины; 9) фармацевтическое образование, 10) краткие сообщения, 11) дискуссии, рецензии, юбилеи, научные школы, история фармации и фармакологии, 12) рекламные материалы.

Общими критериями для публикации статей в журнале «Фармация и фармакология» являются актуальность, новизна материала и его ценность в теоретическом и/или прикладном аспектах. Редакция обеспечивает рецензирование рукописей.

Статьи представляются в редакцию только в электронном виде по адресу pharmjournal@mail.ru или rio.pmfi@gmail.com в формате *.doc или *.docx.

Текст должен быть напечатан черным шрифтом TimesNewRoman (кегль 14), с межстрочным интервалом 1,5 с полями: сверху, снизу - 20 мм, слева - 30 мм, справа - 20 мм. Все страницы должны быть последовательно пронумерованы.

Для оригинальной статьи суммарный объем не должен превышать 15 страниц (формат бумаги А4), для краткого сообщения - 4 страницы. Объем и оформление других видов работ (обзор, лекции или иное) согласуются с редакцией заранее.

Рукопись оригинальных статей (и кратких сообщений) должна включать в себя следующие разделы: 1) титульный лист; 2) резюме; 3) ключевые слова; 4) введение; 5) материалы и методы; 6) результаты и их обсуждение; 7) выводы; 8) список литературы. Структура обзорных статей в пунктах 5-7 может быть иной.

Титульный лист оформляется на отдельной странице и включает УДК, название статьи, количество рисунков и таблиц, фамилию, имя, отчество, ученую степень и ученое звание, место работы, е-таil, область научных интересов каждого автора, а также их подписи. Если авторов несколько, то сведения и подписи указываются в порядке очередности, установленной ими самими с обязательным указанием автора для переписки. Титульный лист может быть отправлен в редакцию по электронной почте (фотография или в отсканированном виде).

Резюме точно отражает содержание статьи и включает актуальность, цель исследования, материалы и методы, результаты, выводы. Общий объем не должен превышать 200-250 слов. Обязательно приводится 3-7 ключевых слов.

Во введении отражается актуальность работы, ставится цель исследования или выдвигается гипотеза. В разделе «Материалы и методы» подробно перечисляются методы исследования, в том числе статистические, аппаратура, реактивы, для растительного сырья место и время заготовки.

Результаты представляют в тексте, таблицах или рисунках в логической последовательности, начиная с основных или наиболее важных сведений. Не следует повторять в тексте данные, указанные в таблицах или на рисунках.

Каждая таблица должна иметь номер (арабскими цифрами) и название (без сокращений). В тексте приводится обязательное указание, например, табл. 1. Все графы в таблице должны иметь заголовок, все сокращения расшифрованы в примечании к таблице.

Рисунки располагаются непосредственно в тексте после первого упоминания. Также они должны быть дополнительно приложены в электронном виде в форматах *.tif, *.pcx, *.bmp, *.jpeg (*.xls, *.xlsx, *.ppt, *.pptx для графиков и диаграмм). Рисунок должен включать минимальное число обозначений, все пояснения выносятся в подпись под рисунком.

Для экспериментальных исследований рекомендуется начать обсуждение, кратко суммировав основные данные, затем проанализировать возможные механизмы или толкование этих данных, сравнить и сопоставить результаты других соответствующих исследований, указать ограничения исследования и проанализировать возможное применение полученных результатов в предстоящих исследованиях и практике.

Список литературы составляется в алфавитном порядке, на отдельной странице в соответствии с ГОСТ Р 7.0.5-2008 «Библиографическая ссылка». Когда число авторов превышает 3, используются формулировки «еt al.» и «и др.». Ссылки в тексте статьи обозначаются арабскими цифрами в квадратных скобках (например, [1]). Фамилии иностранных авторов в тексте даются в оригинальной транскрипции.

В материалах, направленных в журнал, должна быть использована система СИ. Все аббревиатуры, используемые в статье, должны быть расшифрованы, кроме символов химических элементов и сокращенных названий общеизвестных метрических единиц.

Направление в редакцию работ, уже переданных в другие издания или напечатанных в них, не допускается. Рукописи, не принятые к печати, авторам не возвращаются. Рукописи, оформленные с нарушением правил, редакцией не рассматриваются. Редакция оставляет за собой право публиковать принятые к печати статьи в том виде и последовательности, которые представляются оптимальными для журнала. 